\title{
Driving pressure is not associated with mortality in mechanically ventilated patients without ARDS
}

Michael J. Lanspa ${ }^{1,2^{*}}$ (D, Ithan D. Peltan ${ }^{1,2}$, Jason R. Jacobs ${ }^{1}$, Jeffrey S. Sorensen ${ }^{1}$, Lori Carpenter ${ }^{1}$, Jeffrey P. Ferraro ${ }^{3,4}$, Samuel M. Brown ${ }^{1,2}$, Jay G. Berry ${ }^{5}$, Raj Srivastava ${ }^{6,7}$ and Colin K. Grissom ${ }^{1,2}$

\begin{abstract}
Background: In patients with acute respiratory distress syndrome (ARDS), low tidal volume ventilation has been associated with reduced mortality. Driving pressure (tidal volume normalized to respiratory system compliance) may be an even stronger predictor of ARDS survival than tidal volume. We sought to study whether these associations hold true in acute respiratory failure patients without ARDS.

Methods: This is a retrospectively cohort analysis of mechanically ventilated adult patients admitted to ICUs from 12 hospitals over 2 years. We used natural language processing of chest radiograph reports and data from the electronic medical record to identify patients who had ARDS. We used multivariable logistic regression and generalized linear models to estimate associations between tidal volume, driving pressure, and respiratory system compliance with adjusted 30-day mortality using covariates of Acute Physiology Score (APS), Charlson Comorbidity Index (CCl), age, and $\mathrm{PaO}_{2} / \mathrm{FiO}_{2}$ ratio.

Results: We studied 2641 patients; 48\% had ARDS ( $n=1273)$. Patients with ARDS had higher mean APS (25 vs. 23 , $p<.001$ ) but similar CCI (4 vs. 3, $p=0.6)$ scores. For non-ARDS patients, tidal volume was associated with increased adjusted mortality (OR 1.18 per $1 \mathrm{~mL} / \mathrm{kg}$ PBW increase in tidal volume, Cl 1.04 to $1.35, p=0.010$ ). We observed no association between driving pressure or respiratory compliance and mortality in patients without ARDS. In ARDS patients, both $\Delta \mathrm{P}(\mathrm{OR} 1.1, \mathrm{Cl} 1.06-1.14, p<0.001)$ and tidal volume (OR 1.17, $\mathrm{Cl} 1.04-1.31, p=0.007)$ were associated with mortality.
\end{abstract}

Conclusions: In a large retrospective analysis of critically ill non-ARDS patients receiving mechanical ventilation, we found that tidal volume was associated with 30-day mortality, while driving pressure was not.

Keywords: Driving pressure, Lung protective ventilation, Low tidal volume ventilation, ARDS, Respiratory compliance

\section{Introduction}

Mechanical ventilation with high tidal volumes may damage the lung through alveolar overdistension (volutrauma and barotrauma) and by releasing inflammatory cytokines (biotrauma) into the systemic circulation [1-3]. Lungprotective ventilation limits tidal volume and distending pressure on the alveolus in order to prevent mechanical

\footnotetext{
* Correspondence: michael.lanspa@imail.org

${ }^{1}$ Division of Pulmonary and Critical Care, Intermountain Medical Center,

Shock Trauma ICU, 5121 S. Cottonwood Street, Murray, UT 84107, USA

${ }^{2}$ Division of Pulmonary and Critical Care, University of Utah, Salt Lake City, UT, USA

Full list of author information is available at the end of the article
}

ventilation-induced lung injury and improves survival in patients with acute respiratory distress syndrome (ARDS). In a randomized clinical trial performed by the National Institutes of Health, National Heart Lung and Blood Institute (NIH/NHLBI) ARDS Network, mortality in patients with ARDS was decreased with volume control ventilation using tidal volume of $6 \mathrm{~mL} / \mathrm{kg}$ versus $12 \mathrm{~mL} / \mathrm{kg}$ predicted body weight $(\mathrm{PBW})$ and targeting a plateau pressure $\left(\mathrm{P}_{\mathrm{PL}}\right)$ of $\leq 30 \mathrm{~cm} \mathrm{H}_{2} \mathrm{O}$ versus $\leq 50 \mathrm{~cm} \mathrm{H}_{2} \mathrm{O}$ [2]. Consequently, professional societies have recommended lung-protective ventilation strategies for patients with ARDS [4].

(C) The Author(s). 2019 Open Access This article is distributed under the terms of the Creative Commons Attribution 4.0 International License (http://creativecommons.org/licenses/by/4.0/), which permits unrestricted use, distribution, and reproduction in any medium, provided you give appropriate credit to the original author(s) and the source, provide a link to the Creative Commons license, and indicate if changes were made. The Creative Commons Public Domain Dedication waiver (http://creativecommons.org/publicdomain/zero/1.0/) applies to the data made available in this article, unless otherwise stated. 
Lung-protective ventilation in patients without ARDS may decrease the development of ARDS, pulmonary complications, and mortality [3,5-8]. A meta-analysis of mechanically ventilated non-ARDS patients demonstrated that a mean tidal volume of $6.5 \mathrm{~mL} / \mathrm{kg}$ versus $10.6 \mathrm{~mL} / \mathrm{kg}$ PBW resulted in less development of acute lung injury or ARDS, fewer pulmonary infections, and lower mortality [6]. Further evidence of benefit from lung-protective ventilation is supported by a systematic review and patient-level analysis that demonstrated a lower incidence of ARDS and fewer pulmonary complications in non-ARDS patients treated with a tidal volume of $<7 \mathrm{~mL} / \mathrm{kg}$ PBW [7]. However, lung-protective ventilation may not be optimal for all non-ARDS patients. In non-ARDS patients, the functional lung volume is greater, and lung-protective ventilation may cause ventilation-perfusion mismatch, alveolar hypoventilation, and patient-ventilator dyssynchrony [5]. In contrast to the aforementioned studies, a recent prospective randomized clinical trial found no benefit to targeting a tidal volume of $6 \mathrm{~mL} / \mathrm{kg}$ PBW versus $10 \mathrm{~mL} /$ $\mathrm{kg}$ PBW while keeping $\mathrm{P}_{\mathrm{PL}}$ below $25 \mathrm{~cm} \mathrm{H}_{2} \mathrm{O}$ in nonARDS patients [9].

In patients with ARDS, tidal volume normalized to respiratory system compliance (driving pressure) may be a better predictor of survival than tidal volume scaled to normal lung volume using PBW determined by height and sex $[10,11]$. Driving pressure $(\Delta \mathrm{P})$ is the difference between $P_{P L}$ and positive end expiratory pressure (PEEP) and can be influenced by changes in tidal volume or PEEP, or respiratory system compliance. Lowering tidal volume decreases $\triangle \mathrm{P}$. Raising PEEP can also decrease $\Delta \mathrm{P}$ if significant lung recruitment occurs. Despite the association of $\triangle \mathrm{P}$ and mortality in patients with ARDS, this association is less clear in non-ARDS patients. One prior single-center study of non-ARDS patients suggested lack of an association between $\Delta \mathrm{P}$ and mortality, but this finding has not been externally validated in a larger population [12]. Some authors suggest that $\Delta \mathrm{P}$ may be a goal in itself for ARDS management, using $\Delta \mathrm{P}$ as a threshold for safety to decrease ventilator-induced lung injury [13].

To assess the association between tidal volume and $\triangle \mathrm{P}$ on mortality in non-ARDS patients, we analyzed mechanically ventilated patients in intensive care units (ICUs) at Intermountain Healthcare, the largest healthcare system in the Intermountain West, comprising 23 hospitals in Utah and Idaho. Our objective was to determine whether tidal volume and $\Delta \mathrm{P}$ are associated with mortality in mechanically ventilated patients without ARDS. We hypothesized that increased tidal volume and increased $\Delta \mathrm{P}$ are both associated with increased mortality in non-ARDS patients.

\section{Methods}

\section{Design}

We conducted a retrospective cohort study of mechanically ventilated patients in adult medical, surgical, trauma, and cardiac ICUs at 12 hospitals in Utah and Idaho over a 2-year period from January 1, 2014, to December 31, 2015. This study was approved with waiver of informed consent by the Intermountain Healthcare Institutional Review Board.

\section{Population}

We included patients at least 18 years old who had initiation of volume-control or adaptive pressure control (APC) using pressure-regulated volume control (PRVC) mechanical ventilation in the emergency department or ICU and who were mechanically ventilated for at least $24 \mathrm{~h}$. We excluded patients whose initial mode of mechanical ventilation was pressure control, airway pressure release ventilation, pressure support (PS), or continuous positive airway pressure (CPAP), as we wished to assess patients in whom the clinician selected a tidal volume, patients receiving chronic mechanical ventilation, and patients with missing or extreme values ( $>$ 99th percentile, to account for charting errors) of key data elements $\left(\Delta \mathrm{P}\right.$, tidal volume, or $\left.\mathrm{C}_{\mathrm{RS}}\right)$. Only the first episode of qualifying mechanical ventilation was analyzed for any given patient.

This study had two cohorts: patients without ARDS (primary cohort for analysis) and patients with ARDS (analyzed for known association of increased $\triangle \mathrm{P}$ and tidal volume with mortality). We identified ARDS patients using the Berlin definition of ARDS [14] (Additional file 1: Table S1): (i) presence of an ARDS risk factor (trauma, pneumonia, sepsis, aspiration, shock, acute pancreatitis, or drug overdose) using claims data (Additional file 1: Table S2), (ii) ratio of partial pressure of arterial oxygen to fraction of inspired oxygen (P/F ratio) $\leq 255$ on at least $5 \mathrm{~cm}$ $\mathrm{H}_{2} \mathrm{O}$ PEEP (altitude corrected for Salt Lake City barometric pressure of $645 \mathrm{mmHg}$ from a $\mathrm{P} / \mathrm{F}$ ratio $\leq 300$ ) [2], (iii) pulmonary artery occlusion pressure $\leq 18 \mathrm{mmHg}$ if a right heart catheter was present, and (iv) chest radiograph (CXR) indicated bilateral infiltrates not due to effusion, atelectasis, or nodules [12, 15].

Considering the large number of patient records, we used natural language processing (NLP) of CXR reports to determine whether a patient met the fourth criterion of the Berlin definition of ARDS. We validated the NLP tool by testing it against a gold standard cohort of CXR reports read by radiologists on which the statistical NLP tool had not been trained, which included 1144 patients prospectively enrolled and confirmed as having ARDS for previous NHLBI studies at Intermountain Healthcare. The validated sensitivity, specificity, positive predictive value, and negative predictive value of the NLP 
tool were $0.81,0.96,0.86$, and 0.94 , respectively, with a corresponding $\mathrm{F}_{1}$ score of 0.83 and area under the receiver operating characteristic curve of 0.882 .

\section{Exposure and outcome measures}

We obtained data from Intermountain's Electronic Data Warehouse, a carefully curated database integrating patient-level data from multiple clinical, billing, and administrative sources. Data on 30-day mortality (the primary outcome) were obtained using an existing linkage to Utah state death records. The primary exposure was the day 1 average $\Delta \mathrm{P}$ of assessments performed every $2 \mathrm{~h}$. The ventilator protocol instructs the respiratory therapist to measure of $\mathrm{P}_{\mathrm{PL}}$ every $2 \mathrm{~h}$ using an endinspiratory pause, often using a series of breaths averaged to get a value. We measured $\triangle \mathrm{P}$ as $\mathrm{P}_{\mathrm{PL}}-$ Set PEEP $=$ $\Delta \mathrm{P}$, in $\mathrm{cm} \mathrm{H}_{2} \mathrm{O}$. The secondary exposures were day 1 average tidal volume and respiratory system compliance. Measured tidal volume was calculated using a timeweighted average of all measured tidal volumes obtained from the ventilator for day 1 . Measurement of tidal volume was calculated from the ventilator as minute ventilation divided by respiratory rate. The Charlson Comorbidity Index was obtained from pre-admission billing diagnosis codes [16]. We used the lowest P/F ratio within $24 \mathrm{~h}$ after receipt of mechanical ventilation. APS score was calculated using data from the first $24 \mathrm{~h}$ before and after receipt of mechanical ventilation [17]. Ventilator-free days were calculated as days alive and free from ventilation out of 28 days.

\section{Statistical analysis}

Our prespecified primary aim was to assess the association between $\Delta \mathrm{P}$ and 30-day post-intubation mortality in non-ARDS patients. We performed logistic regression of $\triangle \mathrm{P}$ vs. mortality while controlling for Acute Physiology Score (APS), Charlson Comorbidity Index (CCI), age, and $\mathrm{P} / \mathrm{F}$ ratio. Our secondary aims included assessment of the association of set tidal volume and $C_{R S}$ on mortality, ventilator-free days (out of 28 days), and ICU length of stay, separately, in non-ARDS patients. We also sought to confirm the expected associations of $\Delta \mathrm{P}$, set tidal volume, and $C_{R S}$ on mortality, ventilator-free-days, and ICU length of stay in patients with ARDS. Primary and secondary analyses relied on complete-case analysis, so we conducted a sensitivity analysis and imputed missing values using multiple imputation with chained equations (MICE) [18]. Finally, we conducted an additional set of sensitivity analyses using generalized additive models (GAM) with tensor product smooths-a flexible extension of generalized linear models-to capture nonlinear interactions, based on a recent simulation study of ARDS patients that suggested a non-linear relationship between tidal volume and mortality [19-21].

\section{Results}

From 2014 to 2015, we identified 8813 patients who started invasive mechanical ventilation at 17 ICUs from 12 Intermountain Healthcare hospitals. Volume-control ventilation was used in $91 \%$ of patients for initial ventilator settings. After exclusions, 2624 patients were eligible for enrollment, 53\% with ARDS $(n=1385)$ and $47 \%$ without ARDS ( $n=1239)$ (Fig. 1). Relevant patient characteristics are detailed in Table 1 and Additional file 1: Table S3.

Patients with ARDS had higher mean acute physiology scores (25 vs $23, p$ value $<0.001)$ than non-ARDS patients but had similar comorbidities (CCI 4 vs. 3, $p$ 0.38). Patients with ARDS had higher $\Delta \mathrm{P}\left(11\right.$ vs $10 \mathrm{~cm} \mathrm{H}_{2} \mathrm{O}$, $p<0.001$ ), higher PEEP ( 8 vs $5 \mathrm{~cm} \mathrm{H}_{2} \mathrm{O}, p<0.001$ ) and lower set tidal volumes (6.3 vs $6.6 \mathrm{~mL} / \mathrm{kg} \mathrm{PBW}, p=0.04$ ). ARDS patients had fewer ventilator-free days (18 vs 21 , $p<0.001$ ), longer ICU length of stay (7.8 vs 6.2 days, $p<$ $0.001)$, and had higher 30 -day mortality $(34.1 \%$ vs $28.7 \%$, $p=0.004)$.

We observed that among ARDS patients, receipt of APC ventilation was associated with lower set tidal volumes ( $6.5 \mathrm{vs} 6.8 \mathrm{~mL} / \mathrm{kg}, p=0.008)$ compared to tidal volumes of patients on other volume-controlled ventilatory modes. We also noted that delivered tidal volume was higher than set tidal volume $(6.8$ vs. $6.3 \mathrm{~mL} / \mathrm{kg}, p<$ $0.001)$. This pattern was also observed in non-ARDS patients (6.9 vs $6.6 \mathrm{~mL} / \mathrm{kg}, p=<0.001)$. Patients receiving APC were more likely to have delivered tidal volume < $6.5 \mathrm{~mL} / \mathrm{kg}(39.4 \%$ vs $28.1 \%, p<0.001)$.

In our primary regression model of the association between set tidal volume and 30-day mortality among non-ARDS patients, tidal volume was associated with mortality (OR 1.22 per $1 \mathrm{~mL} / \mathrm{kg}$ PBW increase in tidal volume, $95 \% \mathrm{CI} 1.06$ to $1.39, p=0.010$ ). By contrast, $\Delta \mathrm{P}$ was not associated with mortality in non-ARDS patients. In ARDS patients, both $\Delta \mathrm{P}$ and tidal volume were associated with mortality. We observed no adjusted association between $C_{R S}$ and mortality in either cohort. Table 2 lists coefficient estimates, and Fig. 2 displays partial dependency plots. Results were unchanged after multiple imputation to allow inclusion of patients with missing data. As a post hoc analysis, we repeated the regression models, including covariates of spontaneous breathing (defined as a measured respiratory rate $>$ set respiratory rate), we found that neither spontaneous breathing nor its interaction with driving pressure were significant in either patients with or without ARDS and that the inclusion of this interaction term in the models had no effect on the significance of other covariates.

Our generalized additive models demonstrated a nonlinear relationship but similar results between tidal volume and mortality in patients without ARDS, although the association persisted in patients with ARDS. 


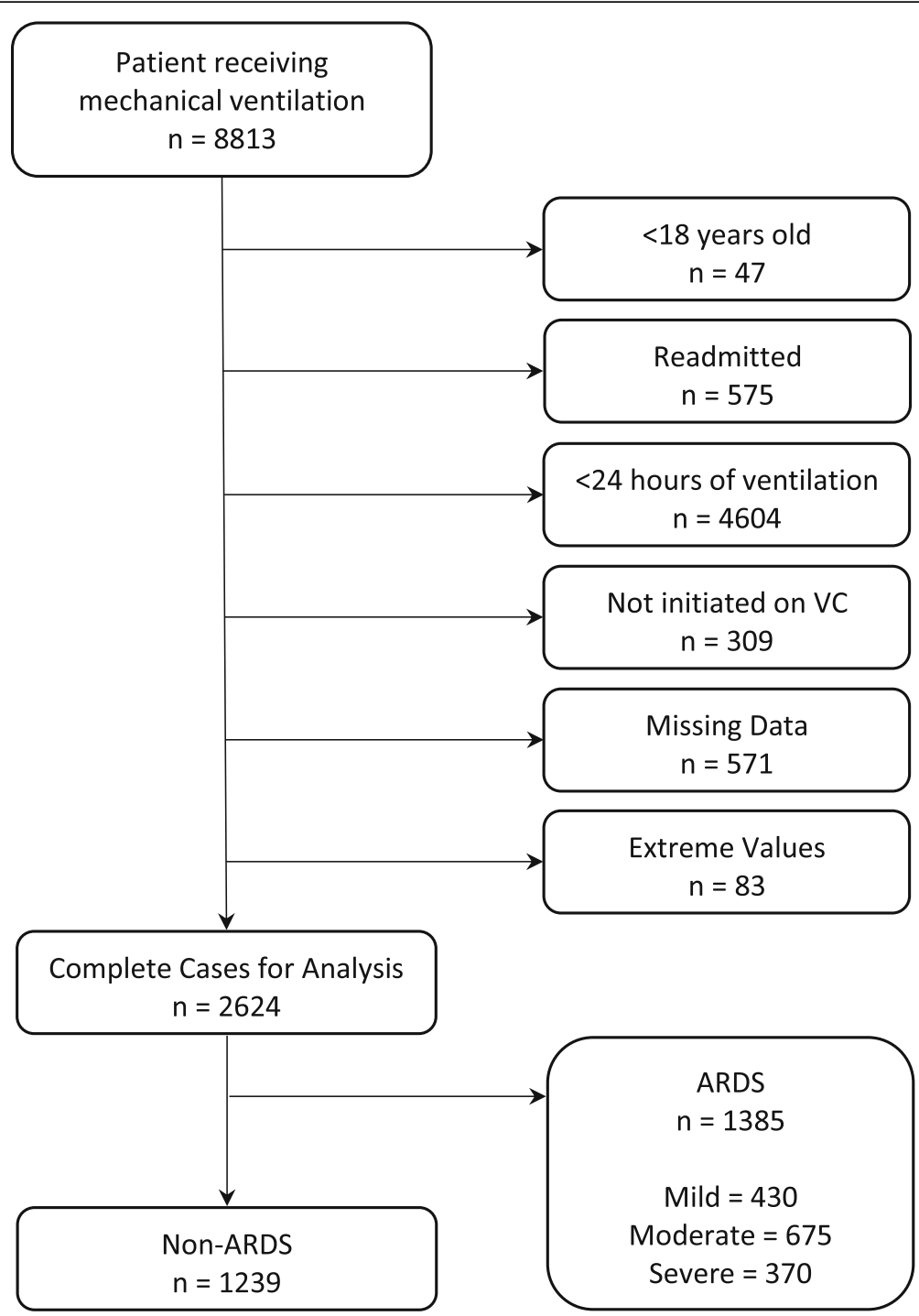

Fig. 1 Patient inclusion diagram. VC: Volume-control ventilation. ARDS: acute respiratory distress syndrome. Extreme values are $>99$ th percentile of $\Delta P$, tidal volume, or $C_{R S}$, attributed to charting errors. Patients with missing values for $\Delta P$, tidal volume, or $C_{R S}$ were excluded from primary analysis, but used for sensitivity analyses after imputing missing values

\section{Discussion}

Our study is, to date, the largest evaluation of the association between $\Delta \mathrm{P}$ and mortality in patients without ARDS. We did not observe a significant association between $\triangle \mathrm{P}$ and mortality in non-ARDS patients, confirming findings from a previous single-center study [12]. This is in contrast to patients with ARDS where $\Delta \mathrm{P}$ is significantly associated with mortality, both in our current study and other previous observational studies and a meta-analysis [10, 11, 22, 23].

The physiologic appeal of driving pressure is that it is essentially the tidal volume corrected for the $C_{R S}$. Among patients with ARDS, who are much more susceptible to ventilator-induced lung injury, there may be some value in this construct. While older studies of
ARDS demonstrated associations between $\mathrm{C}_{\mathrm{RS}}$ and mortality [24], this association appears to be less prominent in the era of lung-protective ventilation [25]. This might explain why we found mortality in ARDS patients was associated with driving pressure and tidal volume to but not with compliance. For non-ARDS patients, while tidal volume is associated with mortality, we observed no relationship between $C_{R S}$ and mortality, suggesting that the volutrauma depends on the relationship of tidal volume to total lung size but not to $C_{R S}$ in non-ARDS patients. One possible explanation for this finding is that $\mathrm{C}_{\mathrm{RS}}$ may not correlate with disease severity in nonARDS patients, unlike ARDS patients, whose disease severity is inversely related to compliance. Obesity, ascites, thoracic, or abdominal surgery may affect respiratory 
Table 1 Demographic and clinical characteristics and clinical outcomes of patients with and without ARDS. Central tendencies are reported as median with interquartile ranges

\begin{tabular}{|c|c|c|c|}
\hline & ARDS $(N=1385)$ & Non-ARDS $(N=1239)$ & $p$ value \\
\hline \multicolumn{4}{|l|}{ Baseline characteristics } \\
\hline Age, years & $61(48-72)$ & $60(44-70)$ & 0.007 \\
\hline Female, \% ( $n)$ & $42.1(583)$ & $42.0(520)$ & 0.98 \\
\hline Acute physiology score & $25(21-30)$ & $23(19-28)$ & $<0.001$ \\
\hline Charlson Comorbidity Index & $4(2-6)$ & $3(1.5-6)$ & 0.38 \\
\hline $\mathrm{PaO}_{2} / \mathrm{FiO}_{2}$ ratio, $\mathrm{mm} \mathrm{Hg}$ & $120(83-170)$ & $194(121-284)$ & $<0.001$ \\
\hline Mild hypoxemia (n) & 340 & 703 & \\
\hline Moderate hypoxemia $(n)$ & 675 & 370 & \\
\hline Severe hypoxemia $(n)$ & 370 & 166 & \\
\hline $\mathrm{PaO}_{2}, \mathrm{~mm} \mathrm{Hg}$ & $78(66-95)$ & $97(76-136)$ & $<0.001$ \\
\hline $\mathrm{PaCO}_{2}, \mathrm{~mm} \mathrm{Hg}$ & $41(35-48)$ & $37(32-43)$ & $<0.001$ \\
\hline \multicolumn{4}{|l|}{ Ventilator parameters on day 1} \\
\hline On PRVC, \% (n) & $74.0(1025)$ & $74.4(922)$ & 0.85 \\
\hline Set $V_{\mathrm{T}}$, normalized to PBW, $\mathrm{mL} / \mathrm{kg}$ & $6.3(6.0-7.6)$ & $6.6(6.0-7.8)$ & 0.04 \\
\hline For patients on PRVC, mL/kg & $6.5(6.0-7.8)$ & $6.8(6.1-7.9)$ & 0.008 \\
\hline For patients on other $V C, m L / k g$ & $6.1(6.0-6.8)$ & $6.1(6.0-6.9)$ & 0.73 \\
\hline Measured $V_{\mathrm{T}}$, normalized to PBW, $\mathrm{mL} / \mathrm{kg}$ & $6.8(6.2-7.8)$ & $6.9(6.3-7.8)$ & 0.06 \\
\hline For patients on PRVC, mL/kg & $6.9(6.2-7.9)$ & $6.9(6.2-7.8)$ & 0.03 \\
\hline For patients on other $V C, m L / k g$ & $6.8(6.4-7.4)$ & $6.7(6.5-7.6)$ & 0.32 \\
\hline Measured $V_{\mathrm{T}}, \mathrm{mL}$ & $452(386-516)$ & $455(392-520)$ & 0.76 \\
\hline Respiratory rate, $\min ^{-1}$ & $23(19-28)$ & $21(18-25)$ & $<0.001$ \\
\hline $\mathrm{FiO}_{2}, \%$ & $45(40-54)$ & $42(40-49)$ & $<0.001$ \\
\hline PEEP, $\mathrm{cm} \mathrm{H}_{2} \mathrm{O}$ & $7.5(5.0-9.9)$ & $5.0(5.0-8.0)$ & $<0.001$ \\
\hline $\mathrm{P}_{\mathrm{PL},} \mathrm{Cm} \mathrm{H} \mathrm{H}_{2} \mathrm{O}$ & $18.7(16.0-21.9)$ & $16.6(14.0-19.6)$ & $<0.001$ \\
\hline$\Delta \mathrm{P}, \mathrm{cm} \mathrm{H}_{2} \mathrm{O}$ & $10.8(8.9-13.2)$ & $10.0(8.1-12.2)$ & $<0.001$ \\
\hline $\mathrm{C}_{\mathrm{RS}}, \mathrm{mL} / \mathrm{cm} \mathrm{H} \mathrm{H}_{2} \mathrm{O}$ & $44.0(34.1-55.4)$ & $46.7(37.8-59.2)$ & $<0.001$ \\
\hline \multicolumn{4}{|l|}{ Clinical outcomes } \\
\hline 30-day mortality, \% (n) & $34.1(472)$ & $28.7(356)$ & 0.004 \\
\hline Ventilator-free days, out of 28 days & $18(0-24)$ & $21(0-25)$ & $<0.001$ \\
\hline ICU length of stay, days & $7.8(4.0-13.5)$ & $6.2(3.3-12.1)$ & $<0.001$ \\
\hline
\end{tabular}

$\mathrm{C}_{\mathrm{RS}}$ static respiratory compliance, $\mathrm{FiO}_{2}$ percent fraction of inhaled oxygen, $\triangle \mathrm{P}$ driving pressure, $\mathrm{PaCO}_{2}$ pressure of dissolved arterial carbon dioxide, $\mathrm{PaO}_{2}$ pressure of dissolved arterial oxygen, $P E E P$ positive end-expiratory pressure, $P R V C$ pressure-regulated volume control ventilation mode, $P B W$ predicted body weight, $P_{P L}$ plateau pressure, $V C$ volume control ventilation, $V_{T}$ tidal volume

Table 2 Adjusted association of tidal volume, driving pressure, and respiratory system compliance with 30-day mortality. Coefficient estimates from multivariable logistic regressions using generalized linear models (GLM). $p$ values were adjusted for multiple hypothesis testing by limiting the false discovery rate (FDR) per the method of Benjamini and Hochberg [9]

\begin{tabular}{lllllll}
\hline Analysis & Group & Outcome & Exposure & OR (95\% CI) & $p$ & $p_{\text {FDR }}$ \\
\hline Primary & Non-ARDS & 30-day mortality & Driving pressure & 1.02 (0.97 to 1.06) & 0.463 & 0.003 \\
Secondary & Non-ARDS & 30-day mortality & Tidal volume & $1.22(1.07$ to 1.39) & 0.01 \\
Secondary & Non-ARDS & 30-day mortality & Compliance & $>1$ (0.99 to 1.01) & 0.890 & 0.89 \\
Confirmatory & ARDS & 30-day mortality & Driving pressure & $1.1(1.06$ to 1.14) & $<0.001$ & $<0.001$ \\
Confirmatory & ARDS & 30-day mortality & Tidal volume & $1.17(1.04$ to 1.31) & 0.007 \\
Confirmatory & ARDS & 30-day mortality & Compliance & $<1(0.99$ to $>1)$ & 0.314 & 0.015 \\
\hline
\end{tabular}



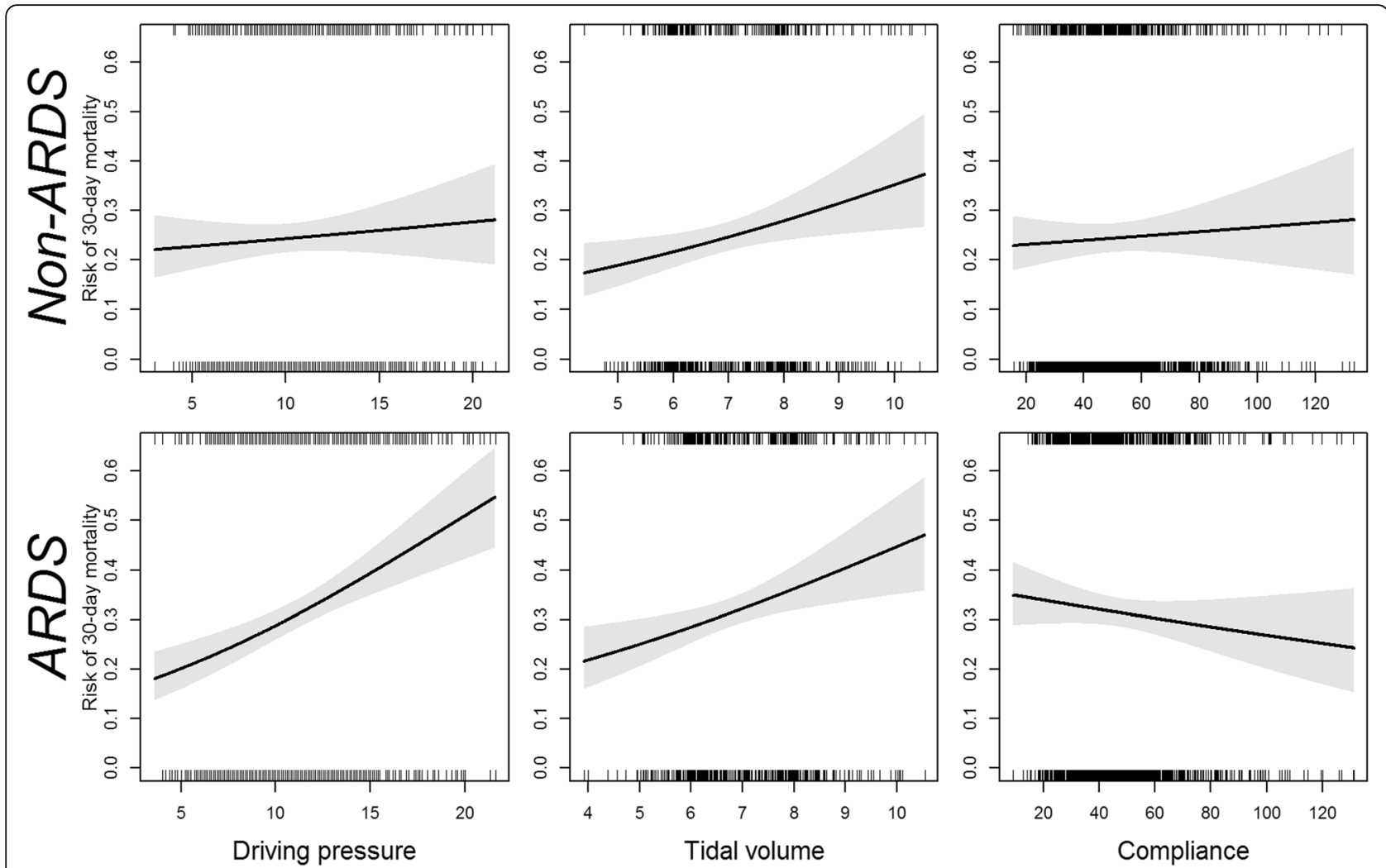

Fig. 2 Estimated risk of 30-day mortality as a function of tidal volume, driving pressure, and respiratory system compliance among patients with and without ARDS, from generalized linear models. Hash marks indicated observed value for the exposures. Gray bands represent \pm 2 standard errors

compliance as well. There may also be some uncaptured confounding by indication among non-ARDS patients, as our generalized additive model for tidal volume in non-ARDS patients demonstrated a u-shaped curve with lower mortality at high tidal volumes. We observed comparable values of $C_{R S}$ and $\triangle P$ between ARDS and nonARDS patients, similar to prior studies [12, 22].

We did identify a significant association between lower tidal volume and improved survival in non-ARDS patients. This association, which supports the findings of other studies in non-ARDS patients [3, 6-8], is not consistent with a recent prospective randomized clinical trial [9]. Our non-linear model suggested a non-linear relationship between tidal volume and mortality in patients without ARDS. One possible explanation for this non-linear relationship might be confounding by indication, where healthier non-ARDS patients might be more likely to receive lower tidal volumes.

We are reassured that our data supports an association between tidal volume and mortality in ARDS patients and supports the recent meta-analysis confirming the association of $\triangle \mathrm{P}$ and mortality in ARDS patients [11]. While the current state of evidence is not mature enough to recommend $\Delta \mathrm{P}$ as a management strategy for
ARDS [26], our data demonstrates no justification at this time to recommend it as a management strategy for non-ARDS patients.

We noted a large percentage of patients in our study cohort were managed with APC ventilation, which is a dual-controlled ventilation wherein the ventilator attempts to achieve tidal volume using a pressure-limited delivery format at the lowest possible airway pressure. While this mode of ventilation may decrease peak inspiratory pressures, no evidence exists that APC improves outcomes [27]. It is possible some of the differences we observed may be confounded by varying management strategies at different ICUs, some of which use APC more than others. The role of respiratory effort may affect the accuracy of $\triangle \mathrm{P}$ in APC. In a passively ventilated patient, $\Delta \mathrm{P}$ might be erroneously interpreted if the flow is not zeroed, while in a spontaneously breathing patient the $\Delta \mathrm{P}$ might be affected by the changes in delivered volume associated with respiratory effort. Synchronization with the ventilator was not consistently recorded and therefore may affect the measurement of $\Delta \mathrm{P}$.

We also note a large percentage (48\%) of patients were categorized as having ARDS. We suspect this bias is 
likely due to the enrichment of our study cohort by restricting to patients who have received mechanical ventilation to $>24 \mathrm{~h}$. Patients with ARDS comprised only $14 \%$ of all patients with mechanical ventilation, but comprised a higher proportion of the study cohort due to the exclusion of patients who received mechanical ventilation $<24 \mathrm{~h}$. One criticism of prior studies that have used radiographic reports to define ARDS is that they may have included patients who might have been less severe by including "ARDS" patients who were liberated from mechanical ventilation within $24 \mathrm{~h}$ [28]. While our NLP method was trained on radiology reports, we validated our tool against clinically confirmed cases of ARDS.

We further noted a low $\mathrm{PiO}_{2} / \mathrm{FiO}_{2}$ ratio among patients without ARDS. We speculate three reasons for the low ratio. First, the exclusion of people intubated for < $24 \mathrm{~h}$ enriches the population with patients who have significant gas exchange. Second, the increased application of high flow nasal cannula and non-invasive positive pressure ventilation likely prevent mechanical ventilation in many patients who would have a $\mathrm{P} / \mathrm{F}$ ratio $>300$. Last, the altitude of Salt Lake City will result in lower $\mathrm{PiO}_{2} /$ $\mathrm{FiO}_{2}$ ratio (about $85 \%$ of what would be expected at sea level).

Our study has several limitations, including those typical of retrospective analysis. As clinicians were free to select ventilator settings, it is likely that there is some residual confounding not accounted for in our analyses. It is possible that the initial setting and mode may be more associated with outcome rather than $\Delta \mathrm{P}$. We analyzed day 1 ventilator settings, and it is possible that these settings may not be representative of the entire hospital course of ventilation. However, a recent study suggested that many initial ventilator settings were unlikely to be changed in the first few days [19]. Our ventilator protocol does not typically advise changes in ventilator mode aside from initiating weaning. The study patients were ventilated for over $24 \mathrm{~h}$, which introduces bias compared to studying patients upon receipt of endotracheal intubation, including the increased proportion of ARDS and relatively high observed mortality in non-ARDS patients. The study ICUs are heterogenous with regard to patient population and with ventilator management preferences, allowing for the possibility of confounding. We did not capture whether patients were triggering the ventilator. In such patients, $\mathrm{P}_{\mathrm{PL}}$ might be a poor surrogate of transpulmonary pressure. Similarly, we did not capture receipt of intravenous cistatricurium or prone positioning, interventions which might affect $\mathrm{P}_{\mathrm{PL}}$ or $\Delta \mathrm{P}$. The cohort of non-ARDS patients comprises several different disease diagnoses, which may limit generalizability to other cohorts with different compositions of diagnoses. Our generalized additive model suggested the relationship between tidal volume and mortality is not linear in nonARDS patients, which may decrease the validity of our primary analysis showing a linear association between tidal volume and mortality. Most study patients were managed with APC, meaning our findings may not be informative for other modes of ventilation.

\section{Conclusions}

In a large retrospective analysis of critically ill nonARDS patients receiving mechanical ventilation, we found tidal volume was associated with 30-day mortality, while $\Delta \mathrm{P}$ was not. While this study supports the use of low tidal volume ventilation in all respiratory failure patients, there is insufficient evidence to justify managing critically ill non-ARDS patients by $\Delta \mathrm{P}$ alone.

\section{Supplementary information}

Supplementary information accompanies this paper at https://doi.org/10. 1186/s13054-019-2698-9.

\section{Additional file 1. Online Data supplement}

\section{Acknowledgements}

None.

\section{Authors' contributions}

All authors participated in drafting and revising this manuscript. All authors read and approved the final manuscript.

\section{Funding}

This study was supported in part by the National Heart, Lung, and Blood Institute (U01HL143505). The content is solely the responsibility of the authors and does not necessarily represent the official views of the National Institutes of Health.

Availability of data and materials

The datasets generated analyzed during the current study are available from the corresponding author on reasonable request.

Ethics approval and consent to participate

Reviewed and approved by Intermountain IRB with waiver of written consent.

Consent for publication

Not applicable.

\section{Competing interests}

The authors declare that they have no competing interests.

\section{Author details}

${ }^{1}$ Division of Pulmonary and Critical Care, Intermountain Medical Center, Shock Trauma ICU, 5121 S. Cottonwood Street, Murray, UT 84107, USA.

${ }^{2}$ Division of Pulmonary and Critical Care, University of Utah, Salt Lake City, UT, USA. ${ }^{3}$ Intermountain Healthcare, Salt Lake City, UT, USA. ${ }^{4}$ Department of Biomedical Informatics, University of Utah, Salt Lake City, UT, USA. ${ }^{5}$ Division of General Pediatrics, Harvard Medical School, Boston, MA, USA. ${ }^{6}$ Healthcare Delivery Institute, Intermountain Healthcare, Salt Lake City, UT, USA. ${ }^{7}$ Division of Inpatient Medicine, Department of Pediatrics, University of Utah and Primary Children's Hospital, Salt Lake City, UT, USA. 
Received: 9 August 2019 Accepted: 9 December 2019

Published online: 27 December 2019

\section{References}

1. Slutsky AS, Ranieri VM. Ventilator-induced lung injury. N Engl J Med. 2013; 369(22):2126-36

2. ARDSNetwork. Ventilation with lower tidal volumes as compared with traditional tidal volumes for acute lung injury and the acute respiratory distress syndrome. The Acute Respiratory Distress Syndrome Network. N Eng J Med. 2000;342(18):1301-8.

3. Determann RM, Royakkers A, Wolthuis EK, et al. Ventilation with lower tida volumes as compared with conventional tidal volumes for patients without acute lung injury: a preventive randomized controlled trial. Crit Care. 2010; 14(1):R1

4. Fan E, Del Sorbo L, Goligher EC, et al. An official American Thoracic Society/ European Society of Intensive Care Medicine/Society of Critical Care Medicine clinical practice guideline: mechanical ventilation in adult patients with acute respiratory distress syndrome. Am J Respir Crit Care Med. 2017; 195(9):1253-63.

5. Davies JD, Senussi MH, Mireles-Cabodevila E. Should a tidal volume of 6 $\mathrm{mL} / \mathrm{kg}$ be used in all patients? Respir Care. 2016;61(6):774-90.

6. Serpa Neto A, Cardoso SO, Manetta JA, et al. Association between use of lung-protective ventilation with lower tidal volumes and clinical outcomes among patients without acute respiratory distress syndrome: a metaanalysis. JAMA. 2012;308(16):1651-9.

7. Neto AS, Simonis FD, Barbas CS, et al. Lung-protective ventilation with low tidal volumes and the occurrence of pulmonary complications in patients without acute respiratory distress syndrome: a systematic review and individual patient data analysis. Crit Care Med. 2015;43(10):2155-63.

8. Futier $\mathrm{E}$, Constantin JM, Paugam-Burtz $\mathrm{C}$, et al. A trial of intraoperative lowtidal-volume ventilation in abdominal surgery. N Engl J Med. 2013;369(5): 428-37.

9. Writing Group for the PI, Simonis FD, Serpa Neto A, et al. Effect of a low vs intermediate tidal volume strategy on ventilator-free days in intensive care unit patients without ARDS: a randomized clinical trial. JAMA. 2018;320(18): 1872-80.

10. Amato MB, Meade MO, Slutsky AS, et al. Driving pressure and survival in the acute respiratory distress syndrome. N Engl J Med. 2015;372(8):747-55.

11. Aoyama H, Pettenuzzo T, Aoyama K, Pinto R, Englesakis M, Fan E. Association of Driving Pressure with Mortality among Ventilated Patients with Acute Respiratory Distress Syndrome: a systematic review and metaanalysis. Crit Care Med. 2018;46(2):300-6.

12. Schmidt MFS, Amaral A, Fan E, Rubenfeld GD. Driving pressure and hospital mortality in patients without ARDS: a cohort study. Chest. 2018;153(1):46-54.

13. Goligher EC, Ferguson ND, Brochard LJ. Clinical challenges in mechanical ventilation. Lancet. 2016:387(10030):1856-66.

14. Force ADT, Ranieri VM, Rubenfeld GD, et al. Acute respiratory distress syndrome: the Berlin definition. JAMA. 2012:307(23):2526-33.

15. Herasevich V, Yilmaz M, Khan H, Hubmayr RD, Gajic O. Validation of an electronic surveillance system for acute lung injury. Intensive Care Med. 2009;35(6):1018-23.

16. Charlson M, Szatrowski TP, Peterson J, Gold J. Validation of a combined comorbidity index. J Clin Epidemiol. 1994:47(11):1245-51.

17. Knaus WA, Draper EA, Wagner DP, Zimmerman JE. APACHE II: a severity of disease classification system. Crit Care Med. 1985:13(10):818-29.

18. Van Buuren S, Groothuis-Oudshoorn K. MICE: multivariate imputation by chained equations in R. J Stat Softw. 2011:45(3):1-67.

19. Lanspa MJ, Gong MN, Schoenfeld DA, et al. Prospective assessment of the feasibility of a trial of low-tidal volume ventilation for patients with acute respiratory failure. Ann Am Thorac Soc. 2019;16(3):356-62.

20. Package 'MGCV' [computer program]. Version R Package Version 2015: $1-72015$.

21. Wood SN. Generalized additive models: an introduction with $\mathrm{R} ; 2017$.

22. Neto AS, Barbas CS, Simonis FD, et al. Epidemiological characteristics, practice of ventilation, and clinical outcome in patients at risk of acute respiratory distress syndrome in intensive care units from 16 countries (PRoVENT): an international, multicentre, prospective study. Lancet Respir Med. 2016:4(11):882-93.

23. Bellani G, Grassi A, Sosio S, et al. Driving pressure is associated with outcome during assisted ventilation in acute respiratory distress syndrome. Anesthesiology. 2019;131(3):594-604.
24. Nuckton TJ, Alonso JA, Kallet RH, et al. Pulmonary dead-space fraction as a risk factor for death in the acute respiratory distress syndrome. N Engl J Med. 2002;346(17):1281-6.

25. Seeley E, McAuley DF, Eisner M, Miletin M, Matthay MA, Kallet RH. Predictors of mortality in acute lung injury during the era of lung protective ventilation. Thorax. 2008;63(11):994-8.

26. Aoyama H, Yamada Y, Fan E. The future of driving pressure: a primary goal for mechanical ventilation? J Intensive Care. 2018;6:64.

27. Guldager H, Nielsen SL, Carl P, Soerensen MB. A comparison of volume control and pressure-regulated volume control ventilation in acute respiratory failure. Crit Care. 1997;1(2):75-7.

28. Villar J, Schultz MJ, Kacmarek RM. The LUNG SAFE: a biased presentation of the prevalence of ARDS! Crit Care. 2016;20(1):108.

\section{Publisher's Note}

Springer Nature remains neutral with regard to jurisdictional claims in published maps and institutional affiliations.
Ready to submit your research? Choose BMC and benefit from:

- fast, convenient online submission

- thorough peer review by experienced researchers in your field

- rapid publication on acceptance

- support for research data, including large and complex data types

- gold Open Access which fosters wider collaboration and increased citations

- maximum visibility for your research: over $100 \mathrm{M}$ website views per year

At BMC, research is always in progress.

Learn more biomedcentral.com/submissions 